\title{
EXPERIÊNCIAS DE FORMAÇÃO DOCENTE EM EJA POR MEIO DO USO DAS TECNOLOGIAS DA INFORMAÇÃO E COMUNICAÇÃO
}

\author{
EXPERIENCES OF TEACHER TRAINING IN ADULT AND YOUTH EDUCATION, \\ THROUGH THE USE OF INFORMATION AND COMMUNICATION TECHNOLOGIES
}

\section{EXPERIENCIAS DE FORMACIÓN DEL DOCENTE EM EJA POR MEDIO DEL USO DE TECNOLOGÍAS DE LA INFORMACIÓN Y COMUNICACIÓN}

\author{
Débora Regina Oliveira Santos \\ Mestranda em Educação de Jovens e Adultos \\ Universidade do Estado da Bahia (UEBA). Salvador-BA, Brasil. \\ deborareginaos@hotmail.com \\ Antonio Amorim \\ Professor Doutor da Universidade do Estado da Bahia (UNEB). \\ Camaçari-BA, Brasil. \\ antonioamorim52@gmail.com \\ Alfredo Eurico da Matta \\ Professor Doutor da Universidade do Estado da Bahia (UNEB). \\ Salvador-BA, Brasil. \\ alfredo@matta.pro.br
}

Resumo: Este artigo investiga a percepção de que as Tecnologias da Informação e da Comunicação trazem uma contribuição para o fazer pedagógico no contexto de Educação de Jovens e Adultos. Queremos saber em que medida o uso das TIC favorece ou não a prática docente da EJA, na rede de ensino do município de Gandu-BA. O objetivo central pretende analisar como as TIC contribuem ou não na formação docente na prática pedagógica da EJA na rede de ensino de Gandu. Pretendemos identificar quais TIC fazem parte da prática pedagógica docente em sala de aula da EJA e elencar as dificuldades encontradas no trabalho do professor da EJA para incorporar as TIC na sua prática pedagógica. A metodologia teve uma abordagem qualitativa, adotando a pesquisa participante enquanto processo procedimental e o questionário para a coleta de informações. Os resultados apontam que o estudo possibilita um suporte teórico necessário ao docente que deseja fortalecer a sua prática educativa em sala de aula. Acreditamos que o uso da tecnologia em sala de aula só terá sentido se ela for utilizada como mediação pedagógica, melhorando o aprendizado dos alunos.

Palavras-chave: Formação docente. Tecnologias da informação e comunicação. Prática pedagógica. EJA.

Abstract: This article investigate the perception that the Information and Communication Technologies (ICT) bring a contribution to the pedagogical doing in the context of Youth and Adult Education (YAE). The general objective was to analyze how ICT contribute or not to the teacher training in the pedagogical practice of the EJA in the educational network of the municipality of Gandu. The specific objectives are: to identify which ICT is part of the pedagogical teaching practice in the classroom of the YAE; to highlight the difficulties encountered in the YAE teacher's praxis in order to incorporate ICT in their pedagogical practice. The problem: to what extent does the use of ICT favor the pedagogical teaching practice of YAE in the teaching network in the municipality of Gandu, Bahia? The methodology had a qualitative approach, adopting the field research regarding the procedural processes and questionnaire for the information collection. The results indicate that the study on technology and pedagogical practice when encouraged in the actions of continuing education of teachers of the YAE. We conclude that the use of technology in the classroom will only make sense if it is used as pedagogical mediation, improving learning.

Keywords: Teacher education. Information and communication technologies. Pedagogical practice. EJA.

Resumen: Este trabajo investiga la percepción de que las tecnologías de información y comunicación traen una contribución que para la práctica pedagógica en el contexto de la enseñanza de Educación de Jóvenes y Adultos. Queremos saber en qué medida el uso de las TIC promueve o no la práctica docente de la EJA en la red de educación del municipio de Gandu-Ba. El objetivo central busca analizar cómo las TIC contribuyen o no en la formación docente en práctica pedagógica de la EJA en la red de enseñanza de Gandu. Tenemos la intención de identificar cuáles TIC 
son parte de la práctica pedagógica docente de la EJA enumerar las dificultades encontradas en el trabajo del profesor de la EJA para incorporar las TIC en su práctica pedagógica. La metodología tuvo un enfoque cualitativo, adoptando la investigación participante como proceso procedimental y cuestionario para la recolección de información. Los resultados muestran que el estudio posibilita un suporte teórico necesario para el docente, que desea fortalecer su práctica educativa en el aula. Creemos que el uso de la tecnología en el aula sólo tendrá sentido si se utiliza como mediación pedagógica, mejorando el aprendizaje de los estudiantes.

Palabras clave: Formación docente. Tecnologías de la información y comunicación. Práctica pedagógica. EJA.

\section{INTRODUÇÃO}

O universo da Educação de Jovens e Adultos (EJA) tem uma característica própria por se constituir de sujeitos que tiveram direitos negados referentes à sua formação e ao seu desenvolvimento pleno. Geralmente, são pessoas de famílias que vivem ou viveram histórias de negação de direitos devido à sua origem étnica, gênero e classe social.

Acreditamos que o contato com as tecnologias pode favorecer novas possibilidades para o desenvolvimento social, intelectual, econômico e político do cidadão. Entretanto, o professor precisa reconhecer a importância do seu papel e refletir sobre a concepção de aprendizagem adotada, relacionando-a com sua prática pedagógica, pois a inovação tecnológica não pode estar a serviço da reprodução dos conhecimentos, baseada meramente no empirismo. É necessário refletir se o uso das tecnologias está favorecendo ou não o processo de ensino-aprendizagem.

Enquanto pesquisadores da área, militando na escola pública municipal, no curso de Mestrado em Educação de Jovens e Adultos da Universidade do Estado da Bahia e no Doutorado em difusão do conhecimento da Universidade Federal da Bahia, temos nos deparado com importantes questionamentos a respeito da formação continuada, do desenvolvimento da prática pedagógica e do uso das tecnologias em sala de aula, especialmente nas classes da EJA.

Nesse contexto, entendemos que a formação inicial e continuada que vem sendo oferecida para os professores precisa ser repensada, pois há uma necessidade emergente de refletir sobre a importância do uso das tecnologias em prol da melhoria do desempenho da escola pública. Diante dessa contextualização, este artigo se debruça sobre o seguinte problema: em que medida o uso das Tecnologias da Informação e Comunicação (TIC) favorece ou não a prática pedagógica docente da Educação de Jovens e Adultos na rede de ensino pública do município de Gandu-BA?

Observamos que se trata da análise de um problema educativo que é um fenômeno contemporâneo, que envolve a sociedade, a escola, os gestores, os professores e os alunos da educação básica de nossas escolas, especialmente, os alunos e os professores da EJA, que passam por diferentes momentos avaliativos de sua formação e da prática pedagógica que utilizam com 0 uso das Tecnologias da Informação e Comunicação.

Por isso, propomos uma análise de como as TIC contribuem ou não na formação docente, na prática pedagógica da Educação de Jovens e Adultos, na rede de ensino do município de GanduBA. Pretendemos identificar quais TIC fazem parte da prática pedagógica docente em sala de aula da EJA; elencar as dificuldades encontradas no trabalho do professor da EJA para incorporar as TIC na sua prática pedagógica; analisar a importância da formação docente e a viabilidade do uso das TIC para a melhoria da prática pedagógica docente na EJA.

O público alvo desta pesquisa foram os docentes do Ensino Fundamental (Tempos Formativos) na modalidade Educação de Jovens e Adultos, de uma Escola Municipal A e de uma Escola Estadual $B$, localizadas no município de Gandu. Por questões éticas, utilizamos nomes fictícios para as referidas escolas e para os professores colaboradores da pesquisa.

Este artigo está organizado por esta introdução, na qual apresenta a problemática referente à pesquisa desenvolvida, intitulada "Experiências de formação docente por meio do uso das TIC", apontando indicativos e encaminhamentos à luz de leituras e de reflexões sobre concepções de EJA, TIC, formação continuada docente e prática pedagógica. No segundo tópico, discutimos os saberes metodológicos: a abordagem qualitativa da pesquisa, indicando os processos procedimentais de estudo de caso; os sujeitos envolvidos na pesquisa; e a caracterização da escola e do instrumento usado no estudo. O terceiro tópico "TIC e práticas pedagógica na EJA" e o quarto tópico "Formação docente e TIC na EJA" são de cunho teórico e discorrem sobre a importância da tecnologia na 
educação com foco na formação do professor orientada para a mudança e a inovação da prática pedagógica mediante o uso das TIC.

O quinto tópico apresenta o resultado da pesquisa com base na aplicação do questionário, evidenciando o olhar do professor da rede de ensino de Gandu, estado da Bahia, sobre a importância e uso das TIC em sala de aula, na perspectiva do fortalecimento da Educação de Jovens e Adultos e da melhoria do desempenho da escola pública. Por fim as considerações e recomendação trarão esclarecimentos sobre a pesquisa, demonstrando em que medida a pesquisa deu conta do problema inicialmente proposto, se os objetivos: geral e específicos foram alcançados, se os procedimentos metodológicos utilizados foram pertinentes, se a bibliografia deu suporte necessário à pesquisa, além de dar sugestões de como trabalhar com o tema.

\section{TRAJETÓRIA METODOLÓGICA E CARACTERIZAÇÃO DA ESCOLA}

Traçar a trajetória metodológica da pesquisa não é uma tarefa simples, pois nos faz refletir sobre as nossas escolhas quanto à natureza, à abordagem, aos objetivos e aos procedimentos metodológicos e técnicos. Cabe, portanto, ao pesquisador elaborar um plano de pesquisa que atenda seus interesses, o objetivo da pesquisa e o problema a ser pesquisado, escolhendo as abordagens mais adequadas e respeitando os pressupostos de cada procedimento de coleta e análise de dados.

Do ponto de vista da forma de abordagem, este trabalho adotou a pesquisa qualitativa, por defendermos que ela compreende a realidade do ser humano e faz intervenção no mundo em que vive, acreditando na relação de interatividade entre as pessoas, o que poderá resultar em uma mudança de comportamento.

A pesquisa qualitativa enfatiza a compreensão de que as pessoas ou os grupos constroem um determinado problema social ou humano, sendo que: "[...] os dados recolhidos são designados por qualitativos, o que significa rico em pormenores descritivos relativamente a pessoas, locais e conversas, e de complexo tratamento estatístico" (BOGDAN; BIKLEN, 1994, p. 16). O pesquisador é o instrumento principal da pesquisa que, por sua vez, aproveita o ambiente natural para coletar os dados necessários para a sua investigação.

Quanto aos processos procedimentais, escolhemos a pesquisa participante por concordar com Brandão e Borges (2007) quando afirmam que se trata de uma investigação social, na qual a comunidade é convidada a participar da análise da sua própria realidade, com o objetivo de promover a mudança social e buscar benefícios para os integrantes da pesquisa. Neste caso, é uma pesquisa educacional voltada para a ação. A pesquisa participante acontece na medida em que o pesquisador interage com os membros da pesquisa. Nesse sentido, tanto o pesquisador quanto os pesquisados identificam o problema, se aprofundam no conhecimento do problema, buscam encaminhamentos e vão para a prática com o intuito de superar as dificuldades do grupo social, e, por fim, avaliam os resultados obtidos.

Segundo Gil (1991, p. 55), "[...] a pesquisa participante, assim como a pesquisa ação, caracterizase pela interação entre pesquisadores e membros das situações investigadas". A população participa de todo o processo da pesquisa. O conhecimento é construído na prática comunitária, na relação estabelecida entre os sujeitos.

Nesta pesquisa, identificamos o problema nas comunidades investigadas, fixamos os objetivos e instrumentos. Em seguida, estabelecemos uma aproximação com os participantes da investigação. Esse momento foi fundamental, porque firmamos uma relação de troca. A princípio, deixamos claro qual era a intenção da investigação e qual o papel do pesquisador e dos participantes para a construção de um contexto colaborativo, esclarecendo as características da pesquisa participante.

Com o intuito de estudar a formação docente com o uso das TIC no contexto da Educação de Jovens e Adultos, escolhemos duas escolas localizadas no município de Gandu. Trata-se de um município baiano, situado no Território do Sul da Bahia, que, segundo o Instituto Brasileiro de Geografia e Estatística (2010), possui uma população de 32.814 habitantes. De acordo com o Censo Educacional (BRASIL, 2015), o referido município tem 81 escolas, com 6.961 alunos matriculados. Segundo os dados do IDEB/INEP (BRASIL, 2015), o município atingiu e ultrapassou o Índice de Desenvolvimento da Educação (IDEB) proposto para 2015, mas não atingiu 6,0. A meta era 4,5 e Gandu obteve 4,7.

Mediante informações cedidas pela equipe da unidade escolar responsável pelo Censo, a Escola Municipal A possui quatrocentos e sessenta e seis alunos matriculados no Ensino Fundamental 
(anos finais), com idade que varia de oito a nove anos, no ensino regular e na modalidade da Educação de Jovens e Adultos. Desse contingente, cinquenta e seis alunos pertencem à EJA, sendo distribuídos em duas turmas: uma no matutino e outra no vespertino.

De acordo com as informações coletadas no Censo Escolar de 2015, a Escola Estadual B tem quatrocentos e sessenta e oito alunos matriculados no Ensino Fundamental (anos finais), com idade variando de oito a nove anos, sendo matriculados no ensino regular e na modalidade da EJA. Desses alunos, setenta e sete compõem o contingente da Educação de Jovens e Adultos.

A coleta de dados realizada com a aplicação de questionários enviados por e-mail com perguntas fechadas e abertas teve como público-alvo dezesseis professores que atuam na EJA das escolas supracitadas. Na elaboração do questionário, foram ponderados os seguintes aspectos: quais Tecnologias de Informação e Comunicação fazem parte da prática pedagógica na sala de aula da Educação de Jovens e Adultos; se existem dificuldades encontradas para incorporar as TIC na prática pedagógica na sala de aula da EJA; a importância e a viabilidade do uso das tecnologias para a melhoria da prática pedagógica docente da EJA; se o professor tem participado de formação continuada para o uso das tecnologias em sala de aula da EJA; e que experiências formativas com as TIC o professor utiliza em sua prática pedagógica e como ela contribui nas mudanças de sua prática. O questionário auxiliou na coleta de dados, pois

[...] é uma maneira indirecta de recolher dados sobre a realidade. Questionando os sujeitos oralmente ou por escrito, tentam obter respostas que: a) exprimam percepções ou opiniões sobre acontecimentos, sobre outras pessoas ou sobre si próprio ou que; b) permitam, por inferência, supor que os sujeitos apresentam capacidades, comportamentos ou processos que não poderiam observar ao vivo. (LESSARD-HÉBERT, 1996, p. 100).

Elaborar um questionário é tentar efetivar, através de perguntas e respostas, questões específicas abordadas nos objetivos da pesquisa, recolhendo amostras dos conhecimentos, sentimentos, atitudes, crenças, normas, concepções e comportamentos, dentre outros, do grupo pesquisado. Além disso, tivemos a observação participante, na qual pudemos dialogar com os sujeitos das duas escolas e efetivar vários momentos de reflexão a respeito dos objetivos da investigação, da situação da EJA na rede municipal de ensino e do uso das tecnologias nesse processo.

Em um segundo momento, estivemos nas escolas para analisar e apresentar encaminhamentos sobre os resultados da pesquisa, destacando a importância do diálogo na comunidade escolar e da efetivação de políticas públicas que auxiliem na melhoria dos processos tecnológicos na prática pedagógica das classes da EJA.

\section{TIC E PRÁTICAS PEDAGÓGICA NA EJA}

Há um crescimento nas pesquisas educacionais do Brasil e do mundo que discutem uma definição do papel do professor. Novas concepções de ensino e de aprendizagem estão se debruçando sobre as teorias de desenvolvimento e de aprendizagem. Junto a isso, as tecnologias da informação e das comunicações exigem novas posturas e novos saberes dos professores, revelando novas metodologias de ensino, técnicas e materiais de apoio, gerando novas buscas de como se dá a aprendizagem.

As Tecnologias da Informação e da Comunicação (TIC) estão sendo expandidas no processo de ensino-aprendizagem, levando em consideração toda uma abordagem didático-pedagógica, que objetiva o desenvolvimento de habilidades e competências nos alunos. O aluno da EJAé influenciado por diferentes mídias e convive com todas elas. A vida, desde cedo, é permeada pela televisão, pelo videogame, pelo telefone, pelo computador, pela internet, pelas redes sociais e por tantos outros recursos eletrônicos. Diante desse novo contexto, a dúvida é como a escola vem dando conta do assunto. Para refletir sobre essas possibilidades, Kenski (2001, p. 105) expressa muito bem que:

As tecnologias digitais permitem aos professores trabalhar na fronteira do conhecimento que pretendem ensinar. Mais ainda, possibilitam que eles e seus alunos possam ir além e inovar, gerando informações novas não apenas no conteúdo, mas também na forma como são viabilizadas nos espaços das redes. Para isso, além do domínio competente para promover ensino de qualidade, é preciso ter um razoável conhecimento das possibilidades e do uso do 
computador, das redes e demais suportes mediáticos em variadas e diferenciadas atividades de aprendizagem.

Não há como negar a presença da cultura digital na vida dos alunos, em todos os níveis e modalidades de ensino. Também, não há como contestar que o diálogo articulado dessas tecnologias com o ambiente escolar traz pistas de como devemos articular uma prática pedagógica, que propicie o ouvir das vozes dos sujeitos, de suas expressões, dos conteúdos que consideram mais pertinentes e os procedimentos metodológicos mais atrativos para a aula, dentre outras questões imbricadas no fazer pedagógico.

Entretanto, nem sempre as escolas percebem a necessidade da inserção da cultura tecnológica nas práticas pedagógicas do professor. Por isso, é necessário repensar novas formas de organização escolar, novas práticas pedagógicas e uma reorganização curricular que estejam atentas ao interesse dos alunos, utilizando as TIC como recursos que motivam a busca do conhecimento.

Nesse sentido, Gadotti (2000, p. 6) afirma que:

\begin{abstract}
Neste começo de um novo milênio, a educação apresenta-se numa dupla encruzilhada: de um lado, o desempenho do sistema escolar não tem dado conta da universalização da educação básica de qualidade; de outro, as novas matrizes teóricas não apresentam ainda a consistência global necessária para indicar caminhos realmente seguros numa época de profundas e rápidas transformações.
\end{abstract}

Sabemos que o desafio é grande. A escola, em busca de cumprir sua função social, garantindo serviços educacionais de qualidade na perspectiva de promover o sucesso da aprendizagem do aluno e sua permanência no sistema de ensino, necessita sensibilizar o professor para o papel das tecnologias como instrumentos que auxiliam na construção de novas possibilidades e, a partir de então, realizar um trabalho articulado das TIC com temas, conteúdos, projetos e programas educacionais.

Julgamos que, quando as TIC chegam à escola, são os professores que determinam quando e como utilizá-las, ou se vão utilizá-las. Sua responsabilidade é grande, pois a maneira de usar a tecnologia vai influenciar os resultados do processo de ensino-aprendizagem e, consequentemente, melhorar a qualidade das suas aulas e o desenvolvimento dos alunos. Acreditamos que essas tecnologias devem ser vistas como um suporte motivador e facilitador do processo de aprendizagem. Instrumentos que auxiliam no atendimento das necessidades desse novo aluno, que é influenciado por diferentes mídias e que deve conviver, naturalmente, com todas elas.

Macedo (2016, p. 109) traz para a discussão a necessidade de utilizar as tecnologias como mediadoras estruturantes das práticas curriculares, chamando a atenção para o uso das TIC nesse contexto técnico e para o impacto socioeducacional que poderá provocar.

\footnotetext{
Potencializadoras de novas/outras maneiras de se estruturar o currículo, as chamadas TICs representam hoje um desafio que vai além do tecnológico quando são transferidas para educação ou produzidas neste cenário social. Incitam problemáticas éticas, políticas, epistemológicas e pedagógico-curriculares. Como com qualquer contexto técnico, faz-se necessário refletir as ambivalências que crivam o seu uso socioeducacional. Até porque, avanço técnico não significa necessariamente avanço social, tampouco educacional.
}

Para o autor, não devemos cair na fascinação das tecnologias como se fossem resolver todos os problemas do ambiente escolar. Entretanto, acredita nas potencialidades que as TIC oferecerem, possibilitando práticas inovadoras. Para ele, a formação e, portanto, o currículo deve contemplar as disponibilidades e os dispositivos tecnológicos em uma perspectiva de inovação pedagógica. Mas, para isso, é inevitável que o professor reflita o modelo de educação inserido nesse currículo.

Dentro desse panorama, é recorrente a necessidade de que o educador utilize a TV, o DVD, rádios, máquina fotográfica, computador, internet, websites, rede sociais e ambientes virtuais de aprendizagem como uma forma de mídia educacional em que a abordagem pedagógica é auxiliada por esses artefatos tecnológicos. Para tanto, evidenciamos a importância de formação continuada para o docente não só para o uso das tecnologias, mas principalmente favorecendo o processo 
de ensino-aprendizagem em busca da melhoria do ensino destinado aos jovens e adultos. Essa discussão será aprofundada no próximo tópico.

\title{
4 FORMAÇÃO CONTINUADA DO DOCENTE E TIC NA EJA
}

Na perspectiva de repensar o trabalho pedagógico com o uso das TIC em sala de aula da EJA, o professor necessita de formação continuada para poder atender as demandas emergentes. Assim, é indispensável refletir sobre o processo de formação oferecida aos profissionais da área de Educação, especialmente, ao professor. Percebemos que há uma distância entre o que se estuda e o que se aplica. Uma separação entre o mundo acadêmico e o da escola.

Tardif (2002) critica o modelo universitário de formação continuada oferecido para os professores. Para ele, o desenho de uma formação continuada não pode privilegiar os conhecimentos científicos, mas respeitar e valorizar os conhecimentos pessoais, culturais e sociais tanto dos professores quanto dos alunos, que incluem: sua trajetória escolar, sua rede de experiências, suas vivências, sua reflexão crítica da prática pedagógica, assim como as singularidades do nível e da modalidade de ensino.

Macedo (2016) amplia essa discussão quando afirma que o trabalho com a formação fortalece o professor, na medida em que se constitui como processo de autorização no qual o docente se vê como coautor de si, protagonista da sua própria ação. Assim, torna essencial o estudo, a investigação e a reflexão da vivência das pautas profissionais do cotidiano. "Enquanto fabricante de políticas de sentidos é mobilizado para discutir, (re) interpretar, criar, propor, via seus etnométodos e, com isso, intercriticamente, formar-se" (MACEDO, 2016, p. 141). Nessa perspectiva, a experiência do professor e seus contextos de atuação se transformam em pautas no cenário formativo.

Geralmente, os cursos de formação continuada para professores não passam de um treinamento feito por técnicos ou especialistas, que transmitem todo seu conhecimento e deixam tarefas a serem seguidas. A formação deve levar em consideração o aprendizado do professor, conquistado durante toda sua vida pessoal e profissional. Saberes e experiências de si devem ser valorizados na reconstrução de suas práticas. Experiências obtidas com os familiares, amigos, alunos e com membros da comunidade escolar e local, dentre outros, também devem ser valorizados.

A ideia da formação continuada deve ser defendida como um espaço de diálogo, que exige uma reflexão prática e, se necessário, mudança de postura. Referente à Educação de Jovens e Adultos, essa formação deve respeitar a diversidade da comunidade, seu conhecimento de mundo, sua experiência de vida, suas peculiaridades, suas diferenças culturais. No entanto, existe uma carência de formação específica, obrigatória, para os profissionais em EJA.

\begin{abstract}
Essa questão ainda desperta muita polêmica, pois alguns educadores entendem que não há necessidade de uma formação específica em EJA, mas que se pode efetuar um trabalho de transversalidade em que possa aparecer a matéria "educação de adultos" ou outras matérias/ disciplinas afins como parte do currículo em diferentes cursos, priorizando-se, neste caso, uma formação geral em Educação. (DANTAS, 2012, p. 152).
\end{abstract}

Notamos que há uma necessidade de voltar um novo olhar para a formação docente da EJA como sendo um espaço institucional, individual e coletivo de construção de saberes, em que o professor não tenha modelos educacionais, mas possa fazer, refazer, experimentar, desafiar, questionar e criticar, inovando as estratégias de aprendizagem dos sujeitos. Nesse sentido, os saberes e o fazer docente transformam-se em objeto de formação continuada que conta com as especificidades dos sujeitos envolvidos na EJA. O aluno dessa modalidade educativa vai além da busca do seu certificado. Ele quer ampliar seus horizontes culturais, garantir direitos que estejam sendo negados, dominar instrumentos necessários ao mundo da informação e exercer sua cidadania.

É nessa perspectiva de inovação, que a EJA, enquanto espaço de aprendizagem, precisa acontecer a partir dos e para os sujeitos concretos envolvidos na ação, tornando-se um espaço de acolhimento e compreensão dos saberes tanto dos professores quanto dos alunos. O professor da EJA necessita pensar em atividades interessantes, reais e motivadoras que mobilizem a participação e o aprendizado daqueles sujeitos que tiveram/têm seus direitos negados. O professor que atua nessa direção necessita de uma prática pedagógica que respeite os diferentes estilos e ritmos de aprendizado do aluno, incentive o trabalho colaborativo em sala de aula, escolha temas e atividades 
de interesse do grupo e oriente o uso das tecnologias incorporadas aos projetos dos alunos, trazendo significativas contribuições à aprendizagem.

Dessa forma, segundo Prado (2005, p. 57):

\begin{abstract}
Essa perspectiva de articulação de saberes exige do professor uma nova postura, o comprometimento e o desejo pela busca, pelo aprender a aprender e pelo desenvolvimento de competências, as quais poderão favorecer a reconstrução da sua prática pedagógica. No entanto, não podemos esquecer que o professor foi preparado para ensinar com base no paradigma da sociedade industrial, em que os princípios educacionais eram pautados na reprodução e na segmentação do conhecimento. Portanto, não basta que o professor tenha apenas acesso às propostas e às concepções educacionais inovadoras condizentes com as sociedades do conhecimento e da tecnologia. É preciso oportunizar a esse profissional a ressignificação e a reconstrução de sua prática pedagógica, voltada para a articulação das áreas de conhecimento e da tecnologia.
\end{abstract}

Destacamos, portanto, a importância da atuação do professor e de seu domínio técnico e pedagógico perante as TIC, para que, embasado em teorias educacionais identifique em quais atividades as mídias têm maior potencial e como devem ser utilizadas na prática docente. Para tanto, o professor precisa estar engajado em programas de formação continuada, interagindo com seus pares e produzindo conhecimento, valorizando as experiências de si e dos outros na construção dessa formação.

Esperamos com esta pesquisa aguçar reflexões referentes ao relacionamento entre o uso das tecnologias e o trabalho pedagógico do professor da EJA, destacando a importância da contribuição do uso inovador tecnológico para uma educação de melhor qualidade. Além disso, esperamos que os estudos sobre tecnologia e prática pedagógica sejam incentivados nas ações de formação continuada de professores da EJA, possibilitando um suporte teórico necessário ao professor que deseja fortalecer sua prática educativa em sala de aula.

Acreditamos que este artigo trará contribuições para o fortalecimento da formação do educador da EJA, na medida em que possibilitará o diálogo com os professores sobre práticas diferenciadas e metodologias inovadoras, o que resultará em uma aprendizagem mais significativa para os alunos da Educação de Jovens e Adultos.

A seguir será apresentada a análise das informações dos dezesseis questionários aplicados sobre a prática pedagógica e as TIC no contexto da Educação de Jovens e Adultos na rede pública de Gandu.

\title{
5 ANÁLISE DA PRÁTICA PEDAGÓGICA E DAS TIC NA VISÃO DOS PROFESSORES
}

Esse foi o momento mais rico da pesquisa, pois possibilitou ao pesquisador refletir se os objetivos propostos foram alcançados. A pesquisa permitiu analisar como as TIC contribuem, ou não, na formação docente e na prática pedagógica da EJA na rede de ensino do município de Gandu. Com a aplicação do questionário aos dezesseis professores da Escola Municipal A e da Escola Estadual $B$, identificamos quais TIC fazem parte da prática pedagógica docente na sala de aula da EJA; elencamos as dificuldades encontradas no trabalho do professor da EJA para incorporar as TIC na sua prática pedagógica; e analisamos a importância da formação docente e a viabilidade do uso das TIC para a melhoria da prática pedagógica docente na Educação de Jovens e Adultos.

As informações adquiridas nessa fase da pesquisa foram analisadas com o auxílio de um gráfico, nuvem de palavras e citações dos professores, todos construídos pelos pesquisadores. Vale ressaltar que, por questão de ética, preservamos os nomes dos professores e das escolas. Os docentes foram representados por números escolhidos de forma aleatória, por exemplo, P1 que significa: Professor $n^{\circ} 1$.

Iniciamos a discussão das informações da pesquisa com o gráfico abaixo, que indica as respostas dos professores ao serem questionados sobre quais Tecnologias da Informação e da Comunicação fazem parte da sua prática pedagógica na sala de aula da Educação de Jovens e Adultos. Eles foram muito contundentes em suas respostas, apresentando um leque de possibilidades para a atuação do professor em sala de aula, tudo para melhorar o desempenho dos seus alunos e tornar o processo de ensino-aprendizagem mais dinâmico e inovador. 


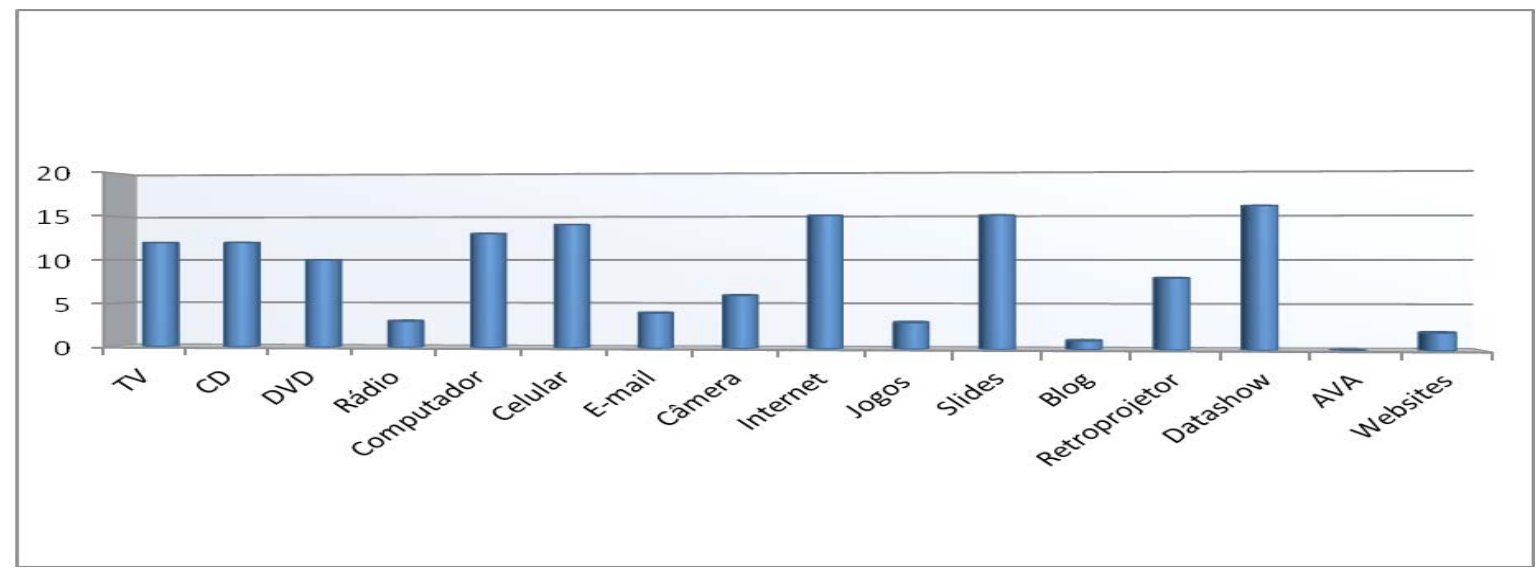

Fonte: Elaborado pelos autores, 2017.

Percebemos que os professores utilizam as TIC em sala de aula, priorizando certas tecnologias em detrimento de outras. Os recursos tecnológicos mais utilizados foram datashow, slides, Internet, computador e celular. As respostas apresentadas no gráfico levam a uma reflexão sobre a apropriação dos conceitos desses recursos pelos docentes. Os professores foram unânimes em dizer que utilizam o datashow, entretanto um não sinaliza a utilização de slides. Esse é um dado interessante, pois o mesmo professor afirma utilizar o datashow em substituição ao retroprojetor. Quinze professores sinalizam o uso da Internet e somente dois apontam fazer uso de websites.

Com isso, podemos afirmar que o professor precisa conhecer as especificidades de cada um dos recursos para incorporá-los, de forma articulada, à sua prática pedagógica. Nesse sentido, o papel do professor é o de fazer uso e dar sentido aos recursos tecnológicos utilizados em sala de aula, descobrindo novas possibilidades de aprendizagem.

O que chamou a atenção foi o uso do celular, pois, dos dezesseis professores pesquisados, quatorze usam esse recurso em sala de aula. Esse dado é relevante, porque o referido aparelho faz parte do cotidiano das pessoas, da rotina dos sujeitos e não seria coerente a escola estabelecer uma dicotomia entre a permissão e a proibição do uso do celular, impedindo, em muitos casos, a entrada desse aparelho em sala de aula. Se os alunos manuseiam diariamente, é bem mais significativo torná-lo um aliado na prática pedagógica. Não devemos incentivar o uso aleatório, mas, planejado, com intencionalidade pedagógica, ou utilizá-lo como um mecanismo de comunicação e de produção de sentidos, exercitando a construção da cultura digital. Tendo em vista a emergência dos celulares na sociedade, cada vez mais presentes no cotidiano das pessoas, parece-nos que a escola e a educação precisam contar com os celulares.

Nessa perspectiva, Bonilla e Pretto (2015, p. 4) afirmam, com bastante propriedade, que:

A convergência de linguagens e mídias, articulada com a conectividade em tempo integral, possibilita a alunos e professores criar, inovar, inventar, entre si e com outros, em espaços e tempos diversos, mantendo-se, ao mesmo tempo, ancorados no local e articulados com o global.

$\mathrm{Na}$ busca da apropriação tecnológica e do uso inovador das TIC em sala de aula, surgem algumas dificuldades para o professor. Na segunda questão lançada no questionário, referente às dificuldades encontradas para incorporar as TIC na prática pedagógica, os professores pesquisados deram respostas que são demonstradas na nuvem abaixo. 
Figura 1 - Fala dos professores sobre as dificuldades encontradas em incorporar as TIC na prática pedagógica

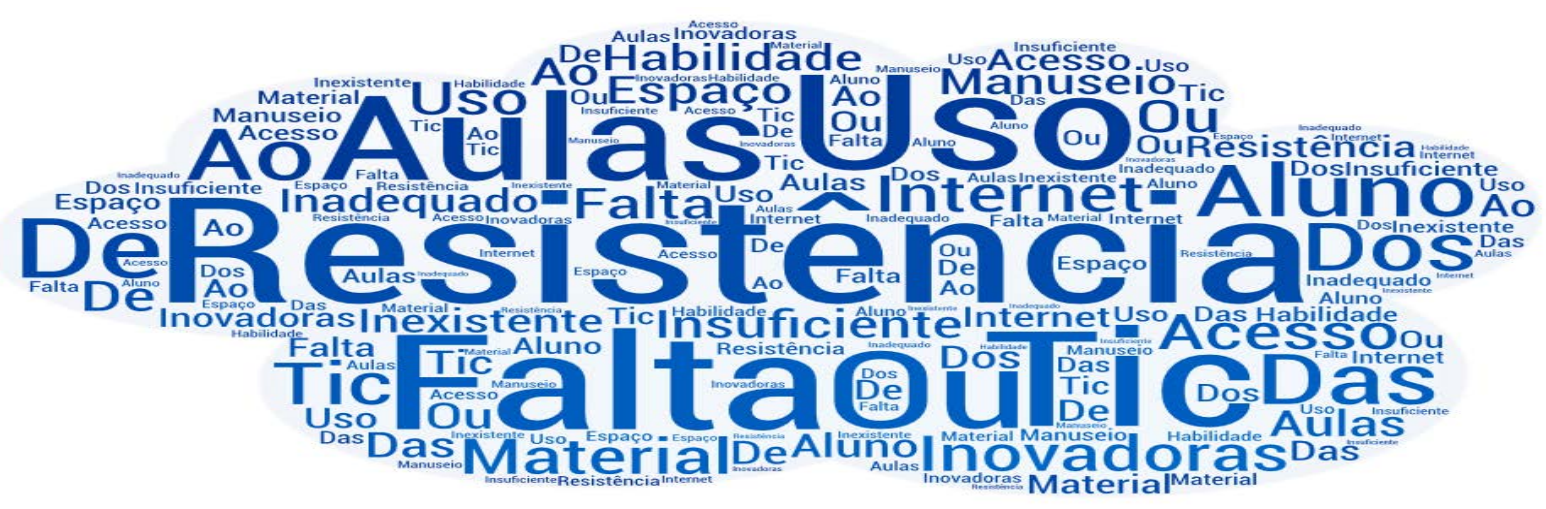

Fonte: Elaborado pelos autores, 2017.

Notamos que as respostas estão centradas no aluno ou na insuficiência dos recursos tecnológicos e/ou espaço adequado para o uso das TIC, pois a maioria dos docentes afirma que encontra dificuldades na falta de habilidade do aluno no manuseio das TIC, no material insuficiente, na resistência dos alunos ao uso das TIC e a aulas inovadoras, no espaço inadequado ou inexistente e na falta de acesso à Internet.

Há uma contradição entre as informações cedidas na primeira e na segunda pergunta. Se a maioria dos alunos desenvolve atividades com o uso do celular, computador e Internet, não se justifica uma falta de habilidade no manuseio das TIC. Vale destacar que o pretendido para a Educação de Jovens e Adultos é que o aluno ultrapasse o manuseio das tecnologias e crie relação de sentido e de autonomia no uso das TIC, que sejam condizentes com essa ideia.

É nessa perspectiva que Oliveira (2012, p. 165) afirma:

E como protagonistas emergentes de uma sociedade em que as tecnologias exercem um papel preponderante, esses sujeitos precisam muito mais do que destrezas no manuseio de tecnologias digitais, necessitam adquirir autonomia e independência no uso das tecnologias de informação e comunicação (TIC). Cada vez mais tomamos consciência de um mundo onde a imersão de crianças, jovens e adultos na comunicação eletrônica é intensa, modificando as formas de agir e provocando novas sociabilidades.

As mídias estão presentes na vida dos alunos, portanto, para incorporá-las na prática pedagógica em sala de aula, não há necessidade de um lugar específico para se trabalhar com as TIC, na verdade é preciso conhecer a funcionalidade de cada tecnologia e pensar de que forma cada uma poderá ser incorporada no cotidiano da sala de aula.

As dificuldades em torno do acesso e da conexão com a Internet é uma fragilidade presente na maioria das escolas brasileiras. A disponibilidade de rede de banda larga ainda é um problema, mesmo que se tenham garantido alguns avanços nos últimos anos. Contudo, é fato que, quando a escola não dispõe de internet, isso dificulta o exercício da cultura digital.

Diante da resistência dos alunos referente ao uso das TIC e a aulas inovadoras, podemos refletir sobre o modelo de educação adotado nas escolas. Muitos alunos e professores oriundos de uma educação bancária sentem dificuldades ao serem convidados a interagir, pensar, refletir e ser um sujeito participativo em seu processo educacional. Como afirma Teixeira (2007, p. 40): "[...] precisamos preparar o homem para indagar e resolver por si os seus problemas". Esse é o grande desafio. Estudos, planejamentos, observações e reflexão da prática devem fazer parte da rotina docente, tendo a tecnologia como motivadora do processo de ensino-aprendizagem. Mesmo que o aluno resista a esse processo, o professor deve insistir em metodologias inovadoras que garantam uma aprendizagem mais significativa. Consideramos ser necessário pensar, mais uma vez, sobre os celulares e em como se transformaram em eletrodoméstico multiuso e cotidiano, pois suas funções já fazem parte da vida das pessoas, que resolvem problemas de seu cotidiano a todo momento com eles. Não podemos esquecer a importância que os aparelhos celulares possuem no uso cotidiano das pessoas, atuando no aprimoramento do diálogo nas redes sociais, de modo que podem ser um importante veículo de comunicação e de pesquisa em sala de aula para acessar a internet, 
gravar, utilizar câmaras, pesquisar mapas, assim como coletar dados e informações que auxiliem no aprofundamento da prática pedagógica e da qualidade do ensino.

No tocante à terceira questão, relacionada à importância e à viabilidade do uso das tecnologias para a melhoria da prática pedagógica docente da Educação de Jovens e Adultos, verificamos que os professores reconhecem a importância das tecnologias para inovação da prática pedagógica, na perspectiva de melhoria do processo de ensino-aprendizagem da EJA. Isso ficou explícito nas falas dos professores:

A aula torna-se mais interessante aos olhos dos alunos, pois os aproximam do mundo da tecnologia, tão fascinante na opinião de muitos deles. O professor tem condições de enriquecer sua aula, utilizando imagens, sons, documentários, tabelas, gráficos e muitos outros, desenvolvendo muitas habilidades tão necessárias às competências na formação dos discentes da Educação de Jovens e Adultos. (P1)

O uso de tecnologias atrai mais os alunos, é interativo. Ao usar as tecnologias, novas ferramentas são utilizadas e não apenas o piloto e quadro negro, ou até mesmo o livro; os alunos que estavam dispersos, começam a se interessar pelas aulas, pois as mesmas ganham vivacidade e ficam mais dinâmicas. (P2)

O uso das TIC pelo professor lhe oportuniza planejar aulas mais significativas, prazerosas e dinâmicas. (P3)

Manter-se atualizado, facilitar a elaboração dos trabalhos, interação entre Professor, Alunos e Escola. (P4)

Oportuniza um ambiente diversificado e incentivador na produção do conhecimento. Contribuir na formação dos alunos para uma sociedade, hoje, informatizada, possibilitando o acesso aos meios modernos de comunicação, incentivando a construção do conhecimento. (P5)

O aluno aprende de forma lúdica. A professora usa os instrumentos tecnológicos que possibilita uma metodologia que desafia os alunos a uma participação direta nas aulas, utilizando-se pesquisa por meio de aprendizagens significativas e da construção do conhecimento, o que os motiva a um processo de investigação. (P6)

A utilização de tecnologia na escola e em sala de aula colabora no acesso, difusão e construção de conhecimento. No entanto, mais do que conhecer as TIC e saber utilizá-las no processo de ensinoaprendizagem, é preciso oferecer uma educação que desperte uma formação crítica e reflexiva, que contribua para a emancipação dos sujeitos.

Concordamos que as TIC oferecem várias possibilidades para realizar um trabalho de cunho pedagógico, além de contribuir na construção da cultura digital. Assistir a um filme na televisão, ouvir uma música no DVD, passar um e-mail para um amigo, acessar um site, compartilhar uma publicação no Facebook, enviar uma mensagem de WhatsApp para o grupo de colegas da escola, jogar no computador e produzir um vídeo são algumas sugestões de atividades que enriquecem a prática pedagógica do professor. Entretanto, não podemos limitar as TIC aos novos usos das máquinas e ao que elas produzem. Elas devem produzir sentidos, alterar comportamentos, informações, saberes e, sobretudo, estar a serviço das mudanças das práticas sociais do aluno da EJA. Professor e aluno não podem se sentir simplesmente usuários dessa tecnologia, mas autores ou coautores de um processo interativo de aprendizagem.

O desafio proposto é reinventar o uso criativo proporcionado pelas TIC, de modo que estimule professor e aluno na busca do aprendizado prazeroso e permanente. Novos caminhos devem ser traçados, adotando novas abordagens pedagógicas. Dessa forma, os sujeitos da EJA são convidados não simplesmente a experimentar uma forma diferenciada do fazer pedagógico, mas a produzir, interagir e participar de uma cultura emergente de superação de dificuldades desta sociedade complexa e plural.

A quarta questão sobre a participação do professor em formação continuada para o uso das tecnologias em sala de aula da EJA revela a escassez das políticas públicas nessa área, pois as respostas dos professores foram unânimes ao afirmar que nunca participaram de formação continuada envolvendo tecnologias e Educação de Jovens e Adultos. Condizente com essa afirmação, escolhemos duas falas que traduzem o coletivo dos professores:

"Não! Falta às escolas uma política de formação continuada para os professores que estão na linha de frente da EJA. Muitos não sabem operar as tecnologias que têm à disposição. (P. 7) 
"Nunca participei. A rede municipal não disponibiliza formação continuada específica para EJA" (P. 8).

Ao analisar as respostas desses sujeitos, percebemos que a importância do processo de formação continuada para professores da EJA é desconsiderada no cenário da educação brasileira. Nesse sentido, Moura (1999, p. 105) alerta que:

Não é possível continuar improvisando educadores e alfabetizadores de Jovens e Adultos. Não é possível continuarmos "zarolhos", olhando enviesados como se a Educação e Alfabetização de Jovens e Adultos fosse uma prática extemporânea e passageira.

Há lacunas na formação continuada para essa modalidade, principalmente no que se refere ao uso das TIC em sala de aula. Essa ausência influencia negativamente o desenvolvimento das práticas pedagógicas do professor. Alguns cursos acontecem de forma aligeirada, pontual, tornandose insuficiente para atender à demanda da Educação de Jovens e Adultos. Condizente com este pensamento, Dantas (2016, p. 131) afirma:

A preocupação com a educação e formação de professores vem aparecendo como uma questão crucial no mundo contemporâneo pressionado pelas demandas e necessidades dos grupos sociais que compõem a sociedade, que clamam por melhores condições de trabalho e qualidade de vida, por acesso à escolaridade gratuita, por ascensão no mundo do trabalho. A pauta emergente nas discussões é a educação de jovens e adultos e o cenário da formação de professores que atuam nesta modalidade educativa.

Para a referida autora, há a necessidade de refletirmos sobre a ideia de formação, especialmente de professores da Educação de Jovens e Adultos, pois esses profissionais precisam lidar com as demandas, as especificidades, as diferenças culturais, as experiências de vida, a trajetória histórica, o leque de conhecimentos e os saberes dos protagonistas que compõem a sala de aula - alunos e professores imbuídos na tarefa de traçar uma identidade para essa modalidade educativa.

Quando a formação continuada busca atender às necessidades e especificidades desses sujeitos, ela: coloca o aluno frente à resolução de problemas, de forma autônoma e emancipatória; estabelece uma relação horizontal e dialógica entre aluno/aluno, aluno/professor, aluno/internauta; valoriza a aprendizagem mútua, na medida em que o professor media a construção do conhecimento do aluno e também aprende com ele; respeita as produções construídas; entende o tempo de aprendizagem de cada sujeito; valoriza as inteligências múltiplas, fortalecendo o processo de aprendizagem; aproveita as diversidades apresentadas no contexto escolar; e cria estratégias que viabilizem o trabalho de autoria e coautoria, dentre outras possibilidades.

Para complementar essa discussão, foi lançada a última pergunta referente às experiências formativas com as TIC e as mudanças na prática pedagógica do professor. Esse questionamento levou o professor a refletir se os cursos oferecidos estão resultando em um planejamento no qual são contempladas atividades pedagógicas com o uso das TIC e se estas favorecem a mudança em sua prática pedagógica. A formação por si só não garante mudança de postura. O resultado se dá mediante o uso que o professor faz das informações obtidas e dos conhecimentos construídos.

Entre os entrevistados, $70 \%$ dos professores afirmaram que realizam as seguintes atividades pedagógicas com o uso das TIC: exibição de filmes e vídeos; músicas; pesquisa na Internet sobre o conteúdo da disciplina; construção de slides, gráficos e tabelas pelos alunos; e elaboração de paródias. Reconheceram que a utilização dessas tecnologias reflete na mudança da prática pedagógica a partir do momento em que o planejamento se torna mais significativo, as aulas mais interativas, mais dinâmicas, e os alunos mais participativos, melhorando a frequência e o desempenho do educando.

Nesse sentido, entendemos que o planejamento das atividades pedagógicas não deve levar a uma imposição das TIC em sala de aula, e sim considerar o posicionamento crítico e pedagógico mediante a análise dos objetivos que se pretende alcançar e dos procedimentos metodológicos que se deseja adotar, para, por fim, decidir se essas tecnologias devem ser incluídas no currículo.

Diante dessa complexidade, surge o desafio da escola de compreender sua relação com os aparatos tecnológicos. A sociedade da informação e comunicação requer uma nova escola, que tenha propostas inovadoras, tanto na maneira de ensinar quanto no modo de aprender. É nesse sentido que pensamos a escola como sendo um ambiente favorável à democratização e à produção do 
conhecimento, ao mesmo tempo em que possibilita a construção e a interpretação das tecnologias, mediante um olhar crítico da linguagem tecnológica, auxiliando o aluno a ser agente transformador, que interfere na realidade da qual faz parte.

\begin{abstract}
Para alcançar esse objetivo, procurando cumprir sua responsabilidade social, a escola precisa contar com professores capazes de captar, entender e utilizar na educação as novas linguagens dos meios de comunicação eletrônicos e das tecnologias, que cada vez mais se tornam parte ativa da construção das estruturas de pensamento de seus alunos. O professor, sintonizado com a rapidez desta sociedade tecnológica e comprometido com o crescimento e a formação de seu aluno, precisará - além de capacidade de análise crítica da sociedade de competências técnicas que o ajudem a compreender e organizar a lógica construída pelo aluno mediante sua vivência no meio social. (SAMPAIO; LEITE, 2013, p. 18-19).
\end{abstract}

Reafirmamos que o professor necessita repensar seu papel em virtude das transformações que a escola vem enfrentando, refletindo sobre sua atuação no processo educativo e sua prática pedagógica de acordo com os desafios lançados pelo avanço tecnológico e pela inserção do aluno nesse contexto. Dessa forma, ele não cairá no "delírio tecnológico", acreditando que a tecnologia irá resolver todos os problemas envolvidos com a EJA. Com um olhar crítico, perceberá os limites, as precariedades e as potencialidades das TIC e das especificidades da referida modalidade de ensino.

Vale ressaltar que somente $25 \%$ dos professores pesquisados fizeram cursos relacionados às tecnologias na Educação. A ausência de participação do professor em cursos de formação envolvendo tecnologias na Educação explica algumas respostas cedidas na primeira questão, quando foi revelado um desconhecimento por parte dos professores sobre nomenclaturas, conceitos e funcionalidades das Tecnologias da Informação e Comunicação. Além disso, isso dificulta o planejamento de estratégias para a sala de aula da Educação de Jovens e Adultos.

Temos a clareza de que a formação continuada é fundamental, mas requer conhecimento das especificidades da EJA e dos sujeitos envolvidos na ação. Pensar a formação do professor da EJA requer uma revisão da prática educativa e do processo de formação inicial e continuada desse professor. A maioria dos professores teve uma formação inicial centrada no aprendizado de crianças, faltando, em seu currículo, uma formação específica para jovens e adultos.

Como afirma Di Pierro (2003, p. 17):

Os docentes que atuam com os jovens e adultos são, em geral, os mesmos do ensino regular. Ou eles tentam adaptar a metodologia a este público específico, ou reproduzem com os jovens e adultos a mesma dinâmica de ensino-aprendizagem que estabelecem com crianças e adolescentes.

Por conta disso, muitas vezes, o professor da EJA, tendo experiência com o ensino regular e sem a formação específica para atuar nessa modalidade, acaba infantilizando as atividades propostas para os alunos ou escolhendo metodologias desinteressantes para seu público-alvo. Portanto, é necessária uma formação voltada para a subjetividade e a vivência dos sujeitos, com compreensão do cenário da prática pedagógica e respeito às peculiaridades da EJA. Paulo Freire (1978, p. 65) contribui com essa discussão quando diz: "[...] a prática de pensar a prática é a melhor maneira de pensar certo". Nesse sentido, acreditamos que o exercício reflexivo sobre a prática se torna indispensável para a ação educativa do professor.

O desafio aumenta quando é preciso associar a formação docente ao uso das tecnologias em sala de aula da EJA. A ideia de capacitação para o uso dos recursos tecnológicos deve ser superada e a formação deve ser vista como espaço de diálogo no qual os envolvidos possam criar novas formas de utilização das TIC, ampliando a inserção digital e fortalecendo o uso pedagógico dessas tecnologias em busca de uma educação pública de melhor qualidade.

\title{
6 CONSIDERAÇÕES FINAIS
}

Chegamos ao final do artigo, destacando o cumprimento da análise da problemática, pois, debruçando sobre o estudo dos conceitos de Educação de Jovens e Adultos, tecnologias de informação e conhecimento, formação continuada e prática pedagógica e, ao investigar em que 
medida o uso das TIC favorece ou não a prática pedagógica docente da EJA, na rede de ensino do município de Gandu, possibilitou constatar que o uso das TIC contribui para a prática pedagógica na medida em que o professor entenda a funcionalidade de cada recurso tecnológico e planeje suas aulas aproveitando as mídias educacionais na construção da autonomia dos alunos da EJA.

Da mesma forma, entendemos que os objetivos foram efetivados ao longo desta reflexão, pois conseguimos analisar como as TIC contribuem ou não na formação docente na prática pedagógica da EJA na rede de ensino do município de Gandu. Além disso, identificamos que TV, DVD, CD, rádio, máquina fotográfica, data-show, retroprojetor, slides, Internet, computador, e-mail, blog, websites, celular e jogos de computador fazem parte da prática pedagógica docente em sala de aula da EJA; elencamos as dificuldades encontradas na práxis do professor da EJA para incorporar as TIC na sua prática pedagógica: falta de habilidade do aluno em manusear as TIC, ao mesmo tempo em que resistem a aulas inovadoras, assim como escassez de acesso à Internet e falta de espaço ou espaço inadequado para o trabalho com as TIC; analisamos a importância da formação docente e a viabilidade do uso das TIC para a melhoria da prática pedagógica docente na Educação de Jovens e Adultos.

Através da pesquisa verificamos a importância do uso das TIC por meio da fala dos professores que afirmam o aumento do interesse dos alunos, da motivação em participar das atividades propostas e da interação entre os colegas, resultando em uma aprendizagem mais significativa. Na medida em que o professor inova, sua prática pedagógica fortalece o processo de ensino-aprendizagem.

Nesse sentido, ganha destaque o investimento na formação continuada do professor que atua na EJA. Uma formação que deve valorizar a construção pessoal e profissional do docente, entendendo as relações construídas em sala de aula pelo educador e educando e respeitando as peculiaridades do contexto da EJA. É imprescindível que o conhecimento construído no espaço da formação continuada se traduza em mudança de postura do professor.

Com esta pesquisa, constatamos a necessidade de uma discussão contínua sobre como o uso das Tecnologias de Comunicação e Informação presentes na vida do aluno e do professor podem favorecer ou não a prática pedagógica inovadora em sala de aula da Educação de Jovens e Adultos. Acreditamos que estudar a teoria, refletir a prática e testar novas atividades são formas de iniciar um processo de mudança na ação educativa. O professor precisa ter consciência de que a adoção das TIC em sala de aula refletirá no processo de ensino-aprendizagem e que, dependendo do seu uso, elas propiciarão a construção do conhecimento e também da cultura digital.

Recomendamos aqui incentivar novas pesquisas sobre a relação dos professores da EJA com as novas tecnologias, apontando caminhos para um investimento na formação continuada, que possibilite a troca de experiência entre os professores sobre as TIC, o que lhes dará suporte para uma prática pedagógica com metodologias inovadoras. 


\section{REFERÊNCIAS}

BOGDAN, R. C.; BIKLEN, S. K. Investigação qualitativa em educação. Tradução Maria João Alvarez, Sara Bahia dos Santos e Telmo Mourinho Baptista. Porto: Porto Editora,1994.

BONILLA, M. H. S.; PRETTO, N. de L. Política educativa e cultura digital: entre práticas escolares e práticas sociais. Perspectiva, Florianópolis, v. 33, n. 2, p. 499-521, maio/ago. 2015.

BRANDÃO, C. R.; BORGES, M. F. A pesquisa participante: um momento da educação popular. Rev. Ed. Popular, Uberlândia, v. 6, p. 5162. jan./dez. 2007.

BRASIL. Ministério da Educação. Instituto Nacional de Estudos e Pesquisas Educacionais Anísio Teixeira. Censo escolar 2015. Brasília, DF, 2015. Disponível em: <http://portal.inep.gov.br/basica-censo>. Acesso em: 20 dez. 2016.

DANTAS, Tânia. Formação de professores da EJA: Uma experiência pioneira na Bahia. Revista da FAEBA: Educação e Contemporaneidade, Salvador, v. 21, n. 37, p.147-162. jan-jun. 2012.

DANTAS, T. R. Formação em EJA: o Programa de Mestrado Profissional como uma proposta inovadora de inclusão social. In: DANTAS, T. R.; AMORIM, A.; LEITE, G. de O. Pesquisa, formação, alfabetização e direitos em educação de jovens e adultos. Salvador: EDUFBA, 2016. p. 131-149. cap. 6.

DI PIERRO, M. C. Seis anos de jovens e adultos no Brasil: os compromissos e a realidade. São Paulo: Ação Educativa, 2003.

FREIRE, P. A alfabetização de adultos: é ela um que fazer neutro? Revista de Educação e Sociedade: o educador precisa ser educado, São Paulo: Cortez, ano 1, n. 1, set. 1978.

GADOTTI, M. Perspectivas atuais da educação. São Paulo, Perspectiva (on-line). 2000, vol.14, n.2, pp.03-11. ISSN 0102-8839. Disponível em: <http://www.scielo.br/scielo.php?pi$\mathrm{d}=$ S0102-88392000000200002\&script=sci_abstract>. Acesso: 19 de abril de 2017.

GIL, A. C. Como elaborar projetos de pesquisa. 3. ed. São Paulo: Atlas, 1991.
INSTITUTO BRASILEIRO DE GEOGRAFIA E ESTATÍSTICA Censo Demográfico de 2010. Características da população. Gandu, 2014: IBGE. Disponível em: <http://cidades.ibge.gov.br/xtras/temas. php? lang $=\&$ codmun $=291120$ \&idtema $=90$ \&search=bahia|gandu|censo-demografico-2010:-resultados-da-amostra-caracteristicas-da-populacao>. Acesso em: 18 dez. 2016.

KENSKI, V. M. O papel do professor na sociedade digital. In: CASTRO, A. D. de; CARVALHO, A. M. P. de (Org.). Ensinar a ensinar. didática para a escola fundamental e média. São Paulo: Ed. Pioneira Thompson Learning, 2001.

LESSARD-HÉBERT, M. Pesquisa em educação. Lisboa: Instituto Piaget, 1996.

MACEDO, R. S. Elaborações curriculares etnoconstitutivas e a formação de professores como reexistência. In: MACEDO, R. S. A teoria etnoconstitutiva de currículo: teoria-ação e sistema curricular formacional. Curitiba: CRV, 2016. p. 139-148.

MOURA, T. M. de M. A prática pedagógica dos alfabetizadores de jovens e adultos: contribuições de Freire, Ferreiro e Vygotsky. Maceió: EDUFAL/INEP, 1999.

OLIVEIRA, M. O. M. Tornar visível o cotidiano na escola: experiências na EJA. Revista da FAEEBA Educação e Contemporaneidade, Salvador, v. 21, n. 37, p. 163-172, jan./jun. 2012.

PRADO, M. E. B. B. Articulações entre áreas de conhecimento e tecnologia. Articulando saberes e transformando a prática. In: ALMEIDA, M. E. B. de; MORAN, J. M. (Org.). Integração das tecnologias na educação. Brasília, DF: MEC; SEED; TV Escola; Salto para o Futuro. p. 54-58, 2005. cap. 1.8.

SAMPAIO, M. N.; LEITE, L. S. Alfabetização tecnológica do professor. 10. ed. Petrópolis: Vozes, 2013.

TARDIF, Maurice. Saberes docentes e formação Profissional. Petrópolis, RJ: Vozes, 2002.

TEIXEIRA, A. Pequena introdução à filosofia da educação. Rio de Janeiro: Editora UFRJ, 2007 